\title{
AVALIAÇÃO DA COMPOSIÇÃO DO EFLUENTE DO PROCESSO DE PRODUÇÃO DE BIODIESEL POR TRANSESTERIFICAÇÃO
}

\author{
S. P. da SILVA ${ }^{1}$, V. V. L. BEZERRA ${ }^{2}$, A. R. P. SCHULER ${ }^{2}$ \\ ${ }^{1}$ UAST - UFRPE - Unidade Acadêmica de Serra Talhada - Universidade Federal Rural de \\ Pernambuco. \\ ${ }^{2}$ LCI-DEQ-UFPE - Laboratório de Cromatografia Instrumental - Departamento de \\ Engenharia Química - Universidade Federal de Pernambuco. \\ E-mail para contato: suzpedroza@gmail.com
}

\begin{abstract}
RESUMO - Diante da crescente expansão da produção de biodiesel em plantas industriais que utilizam o processo de transesterificação com catalisador alcalino, verifica-se a necessidade em tratar o efluente gerado durante este processo produtivo. Logo, caracterizou-se o efluente da produção de biodiesel de uma planta experimental piloto acerca de suas características físico-químicas, servindo como base para trabalhos futuros que visem seu reuso ou disposição final. A caracterização do efluente foi realizada avaliando os seguintes parâmetros: demanda química do oxigênio, demanda bioquímica do oxigênio, série de sólidos, turbidez, condutividade, $\mathrm{pH}$, oxigênio dissolvido, sódio, potássio, temperatura, óleos e graxas. Neste trabalho a maior carga do efluente gerado na produção de biodiesel pelo processo de transesterificação é de característica orgânica, apresentando a maior parte dos parâmetros analisados fora dos padrões de emissão e classificação das águas segundo as resoluções do CONAMA.
\end{abstract}

\section{INTRODUÇÃO}

Tem sido mostrado (Boccardo, 2004) que desde a Revolução Industrial a demanda de energia no mundo cresceu a um ritmo assustador, chegando a níveis tão elevados que, durante as duas primeiras décadas do século XX, a humanidade consumiu mais energia do que em toda sua existência anterior.

A maior parte da energia consumida no mundo provém do petróleo, do carvão e do gás natural, porém essas fontes são limitadas e com previsão de esgotamento no futuro, o que tem motivado o desenvolvimento de tecnologias que permitam utilizar fontes renováveis de energia (Ferrari et al., 2005).

Com a crise energética mundial, buscam-se alternativas renováveis para ampliar a matriz energética que possam substituir, gradativamente, o uso de combustíveis fósseis, evitando, com isso, colapsos no abastecimento (Holanda, 2004). Existe a expectativa de diminuição das reservas de petróleo com a possibilidade da escassez do mesmo. Há também uma grande e crescente preocupação com a preservação do meio ambiente, pois os combustíveis fósseis são grandes poluidores, seja pela emissão de gases do efeito estufa durante a combustão, seja pelo descarte de resíduos ou pelos derramamentos que 
eventualmente ocorrem no mar e no solo. Esses dois fatores têm incentivado alternativas visando à sua substituição (Bonomi et al., 2006).

Neste contexto, destaca-se o biodiesel como uma alternativa para substituição ao óleo diesel em motores de ignição por compressão. O uso do biodiesel como combustível tem sido promissor devido às diversas vantagens apresentadas. É um combustível renovável substituto para o diesel. É preparado a partir de óleos vegetais ou de gordura animal, por meio da transesterificação com alcoóis. Pode ser usado como uma mistura com diesel em qualquer proporção, já que possuem características similares, e, além disso, têm propriedades melhores que as do diesel por ser renovável, biodegradável, não tóxico, livre de enxofre e aromáticos (Lima, 2005).

Diante da crescente expansão da produção de biodiesel em plantas industriais que utilizam o processo convencional de transesterificação com catálise homogênea em meio básico verifica-se a necessidade em tratar o efluente gerado durante este processo produtivo (Jaruwat et al., 2010) de forma que adquira características dentro dos padrões de lançamento de efluentes presentes na Resolução CONAMA n 357 de 17/6/2005. Para tal tratamento existe a necessidade de se conhecer as características físicas, químicas e biológicas.

Foram determinados os parâmetros: demanda química do oxigênio (DQO), demanda bioquímica do oxigênio (DBO), sólidos totais, sólidos voláteis, sólidos fixos, sólidos suspensos, sólidos dissolvidos, sólidos decantáveis, turbidez, condutividade, potencial hidrogeniônico, oxigênio dissolvido, sódio, potássio, temperatura, óleos e graxas.

A avaliação dos parâmetros ocorreu, através das características físico-químicas do efluente obtido, comparando-as com a resolução CONAMA 430/2011 e com a resolução CONAMA 357/2005.

\section{MATERIAL E MÉTODOS}

\subsection{Produção de biodiesel na usina Caetés}

Para cada 1000 litros de biodiesel produzido, são utilizados 130 litros de álcool, mil litros de óleo vegetal e 200 litros de água para lavagem do biodiesel. O subproduto da produção de biodiesel é a glicerina, sendo formados 117 litros.

Para favorecer a formação dos produtos, o álcool é adicionado em excesso, pois a reação é reversível. No final é feito a sua recuperação. O produto reagido deste reator é transferido para dois decantadores em série, onde deve permanecer até separação em duas fases: uma fase leve contém os ésteres (biodiesel) e a outra (mais pesada) a glicerina com álcool de excesso.

Após a separação das fases, a glicerina com álcool de excesso é enviada para o evaporador para a retirada do álcool metílico excedente. Em seguida a glicerina isenta de álcool serve de matéria-prima para a produção de sabão ou indústria química, o álcool recuperado é concentrado em uma coluna de destilação para então ser reaproveitado no processo. 
Já os ésteres (biodiesel) seguem para um processo de purificação para ajuste de $\mathrm{pH}$ e retirada de impurezas. Primeiro foi adicionada água levemente ácida (ácido cítrico) para a neutralização do biodiesel e em seguida é realizada uma lavagem só com água para remover qualquer impureza. Essas lavagens são feitas com $10 \%$ de água em relação à quantidade de biodiesel obtido, em cada. A água de lavagem é separada do biodiesel por centrifugação e o combustível é filtrado e armazenado. Á água de lavagem (neutralizada) é enviada para caixas separadoras de água e óleo para a recuperação de qualquer gordura que possa estar presente na água. Esta gordura será enviada para o tratamento do óleo para ser aproveitada no processo.

A qualidade do biodiesel de Caetés é monitorada através de análises físico-químicas para atendimento as especificações da Agência Nacional do Petróleo, Gás Natural e Biocombustíveis (ANP), de acordo com a Resolução ANP Nº 7, de 19.3.2008.

\subsection{Análise dos parâmetros físico-químicos da água}

As análises dos parâmetros físico-químicos dos efluentes gerados, tanto na produção em bancada como na produção na planta piloto, foram realizadas no Laboratório de Engenharia Ambiental e Qualidade (LEAQ), seguindo as metodologias a seguir:

- Potencial hidrogeniônico (pH): Standard Methods for the Examination of Water and Wastewater (SMEWW) 4500 B: Potenciometria.

- DBO 5 dias: SMEWW 5210 B: Incubação 5d- Det. OD.

- DQO: SMEWW 5220 C: Refluxo fechado/ Titulometria $\left(\mathrm{K}_{2} \mathrm{Cr}_{2} \mathrm{O}_{7}\right)$.

- Sólidos dissolvidos totais: SMEWW 2540 C: filtração em membrana 0,45 mm / Gravimetria.

- Sólidos totais: SMEWW 2540B; Gravimetria.

- Sólidos suspensos totais: SMEWW 2540D: filtração em membrana 0,45 mm / Gravimetria.

- Sólidos fixos e voláteis: SMEWW 2540E: Gravimetria.

- Óleos e graxas: SMEWW 5520 B: Gravimetria.

- Turbidez: turbidímetro, modelo AP 2000-IR da Policontrol.

- Condutividade: Condutivímetro, modelo DM-32 da Digimed.

- Cor: Espectrômetro, modelo Espectroquant NOVA 60 da Merck. 
- Sódio (Na) e Potássio (K): Espectrometria por absorção atômica, modelo SpectrAA 220 FAST SEQUENTIAL da Varian.

\section{RESULTADOS E DISCUSSÃO}

Os valores obtidos na Tabela 1 encontram-se fora dos padrões das resoluções, excetuando-se a temperatura, dentro da possibilidade de emissão, e os sólidos sedimentáveis, dentro da classificação de um corpo hídrico de classe 1 .

Dentre os parâmetros passivos de tratamento, o pH, a condutividade e a turbidez são os mais simples de tratamento referentes aos valores permitidos pela legislação. Neste bloco, também pode ser considerada a cor, pois apesar de um valor elevado, pode ser tranquilamente contornado com um tratamento simples.

Tabela 1- Resultados do efluente ( $1^{\mathrm{a}}$ lavagem), da produção na planta piloto e sua indicação sugerida de destinação.

\begin{tabular}{|c|c|c|c|}
\hline PARÂMETRO & EFLUENTE & INDICAÇÃO & UNIDADE \\
\hline DQO & 345795,80 & Tratamento & $\mathrm{mg}$ de $\mathrm{O}_{2} / \mathrm{L}$ \\
\hline DBO & 278600,00 & Tratamento & $\mathrm{mg}$ de $\mathrm{O}_{2} / \mathrm{L}$ \\
\hline Cor & $>500,00$ & Tratamento & $\mathrm{mg}$ de $\mathrm{Pt} / \mathrm{L}$ \\
\hline Turbidez & 119,00 & Tratamento & UNT \\
\hline $\mathrm{pH}$ & 4,60 & Tratamento & - \\
\hline S. Sedimentáveis & $<0,10$ & Classe 1 & $\mathrm{mg} / \mathrm{L}$ \\
\hline Condutividade & 1411,00 & Tratamento & $\mu \mathrm{S} / \mathrm{cm}$ \\
\hline $\mathrm{O} \& \mathrm{G}$ & 7527,60 & Tratamento & $\mathrm{mg} / \mathrm{L}$ \\
\hline Temperatura & 28,00 & Emissão & ${ }^{\circ} \mathrm{C}$ \\
\hline
\end{tabular}

Entretanto, DQO, DBO, óleos e graxas e cor, possuem valores indicativos de uma elevada carga orgânica, evidenciando uma difícil disposição para o efluente a não ser tratá-lo. Tais valores são considerados absurdos, perante a legislação.

Sozinhos, esses dados não apresentam nenhum significado quanto a destinação do efluente. No entanto, podem fornecer um entendimento do processo de lavagem do biodiesel (Tabela 2).

São observados na Tabela 2 que todos os parâmetros estão fora dos padrões de emissão e classificação referentes às resoluções CONAMA 430 e CONAMA 357, respectivamente. Excetuando-se temperatura e Sólidos sedimentáveis.

Cor, turbidez e $\mathrm{pH}$, apresentam valores, apesar de maiores, próximos dos permitidos na legislação. Dentre os quais, a cor é o parâmetro de maior diferença. 
O valor máximo da turbidez de um corpo hídrico de classe dois é 100 UNT. O pH para emissão de um efluente é de no mínimo 5 e no máximo 9. Logo, os valores de turbidez e pH contidos na Tabela 2 diferem em aproximadamente $10 \%$ do permitido pela legislação.

A cor, no entanto, encontra-se cerca de 4 vezes o valor de um corpo hídrico de classe 2 (75 mg de Pt/L).

A condutividade serve para indicação da salinidade da água, onde valores próximos de $1000 \mu \mathrm{S} / \mathrm{cm}$ são para águas contaminadas industrialmente. $\mathrm{O}$ valor obtido na Tabela 2 apresenta-se próximo a este.

Tabela 2- Resultados do efluente da mistura, da produção na planta piloto e sua indicação sugerida de destinação.

\begin{tabular}{|c|c|c|c|}
\hline PARÂMETRO & EFLUENTE & INDICAÇÃ̃O & UNIDADE \\
\hline DQO & 120752,90 & Tratamento & $\mathrm{mg} \mathrm{de} \mathrm{O}_{2} / \mathrm{L}$ \\
\hline DBO & 55000,00 & Tratamento & $\mathrm{mg}$ de $\mathrm{O}_{2} / \mathrm{L}$ \\
\hline Cor & 310,00 & Tratamento & $\mathrm{mg}$ de $\mathrm{Pt} / \mathrm{L}$ \\
\hline Turbidez & 108,00 & Tratamento & UNT \\
\hline $\mathrm{pH}$ & 4,67 & Tratamento & - \\
\hline S. Sedimentáveis & $<0,10$ & Classe 1 & $\mathrm{mg} / \mathrm{L}$ \\
\hline Condutividade & 981,00 & Tratamento & $\mu \mathrm{S} / \mathrm{cm}$ \\
\hline Ó. \& G. & 827,60 & Tratamento & $\mathrm{mg} / \mathrm{L}$ \\
\hline Temperatura & 28,00 & Emissão & ${ }^{\circ} \mathrm{C}$ \\
\hline
\end{tabular}

Verificando-se os valores de DQO, DBO e óleos e graxas constata-se um efluente com uma alta carga orgânica. Neste efluente, o teor de óleos e graxas encontra-se cerca de 10 vezes menor, quando comparado ao valor obtido pela primeira lavagem, evidenciando um favorecimento do tanque de separação de biodiesel e água. O mesmo teor de óleos e graxas da mistura apresenta cerca de 16 vezes o valor máximo permitido pela resolução CONAMA 430 para emissão.

Analisando DQO e DBO, o resultado torna-se mais coerente quando as mesmas são analisadas de forma conjunta, visto que a DBO é uma contribuinte para a DQO. Assim, foram verificados valores bastante elevados tanto para DQO, quanto para DBO referentes à legislação.

A DBO é indicada diretamente, correspondendo, milhares de vezes acima do valor de corpos hídricos de classe 4. Este corresponde ao máximo valor maior permitido de $10 \mathrm{mg}$ de $\mathrm{O}_{2} / \mathrm{L}$, visto na resolução CONAMA 357. Na esfera de emissão, a resolução CONAMA 430 fornece uma legislação mais flexível, indicando a necessidade de remoção de $60 \%$ do valor, que resultaria no valor final de $22000 \mathrm{mg}$ de $\mathrm{O}_{2} / \mathrm{L}$. Valor este bastante elevado, ou seja, um efluente tóxico.

Comparando os valores da DQO e DBO com dados da literatura, verifica-se que os valores obtidos neste trabalho (Tabela 2) encontram-se bastante elevados. Porém, a 
metodologia de produção do biodiesel, em especial a etapa de lavagem, deve ser analisada, visto que na literatura, em sua maioria, a lavagem é realizada com a proporção de 3 litros de água para cada 1 litro de biodiesel produzido. Vale salientar que neste trabalho houve uma lavagem com 0,2 litros de água, fornecendo um fator de diluição de 15 vezes.

Nota-se uma melhora significativa nos valores da Tabela 2 quando comparados ao efluente da primeira lavagem. A maior contribuição para estes parâmetros se refere ao biodiesel difundido no efluente, visto que após a separação houve uma diminuição desses valores em cerca de metade. Tal diminuição pode ser justificada pela diluição.

Apesar de ocasionar um "efeito de diluição" no efluente gerado, a segunda lavagem é necessária para remoção de $\mathrm{K}$ em excesso, assim como de possíveis resíduos presentes de etapas anteriores.

A Tabela 3 fornece os parâmetros do efluente de primeira lavagem. $\mathrm{O}$ mesmo tem característica orgânica, em virtude das concentrações dos sólidos voláteis se encontrarem mais elevados em comparação com as concentrações dos sólidos fixos.

No quesito tamanho das partículas, os sólidos presentes na primeira lavagem, se encontram em suas formas de menor diâmetro, visto que as concentrações dos sólidos dissolvidos encontram-se mais elevadas que as concentrações dos sólidos suspensos. Tal característica é evidenciada pela elevada quantidade de sais dissolvidos, tanto de sódio quanto de potássio, com o segundo em maior quantidade.

Em relação às concentrações de $\mathrm{Na}$ e $\mathrm{K}$, verifica-se uma pequena concentração de $\mathrm{Na}$ no efluente. Tal fato deve-se ao uso de maior quantidade de $\mathrm{NaOH}$ utilizada na etapa de neutralização do óleo. Referente a concentração de K, observa-se uma alta quantidade do mesmo, devido a sua utilização como parte do catalisador (Metóxido de Potássio) da reação. Apesar de haver uma quantidade retida na glicerina, é através da etapa de lavagem que é garantida a remoção do excesso de K.

Os parâmetros abordados nas Tabelas 3 e 4 servirão como suporte para caracterização físico-química dos efluentes, tanto da primeira lavagem, quanto da mistura.

Tabela 3- Resultados do efluente da $1^{\text {a }}$ lavagem escala piloto.

\begin{tabular}{ccc}
\hline PARÂMETRO & 1 $^{\text {a }}$ LAVAGEM & UNIDADE \\
\hline S. Totais & 16864,00 & $\mathrm{mg} / \mathrm{L}$ \\
S.V. Totais & 11968,30 & $\mathrm{mg} / \mathrm{L}$ \\
S.F. Totais & 4895,80 & $\mathrm{mg} / \mathrm{L}$ \\
S.S. Totais & 35,80 & $\mathrm{mg} / \mathrm{L}$ \\
S.S. Voláteis & 32,80 & $\mathrm{mg} / \mathrm{L}$ \\
S.S. Fixos & 3,00 & $\mathrm{mg} / \mathrm{L}$ \\
S.D. Totais & 16828,30 & $\mathrm{mg} / \mathrm{L}$ \\
S.D. Voláteis & 11935,50 & $\mathrm{mg} / \mathrm{L}$ \\
S.D. Fixos & 4892,80 & $\mathrm{mg} / \mathrm{L}$ \\
Na & 20,030 & $\mathrm{mg} \mathrm{de} \mathrm{Na} / \mathrm{L}$ \\
K & 2366,90 & $\mathrm{mg} \mathrm{de} \mathrm{K} / \mathrm{L}$ \\
\hline
\end{tabular}


Os valores da Tabela 3 não servem como dados conclusivos, e sim indicativos para este trabalho, pois, referem-se à primeira lavagem. Os mesmos servem para uma melhor avaliação quando usados em conjunto com os dados do efluente de mistura, presentes na Tabela 4 a seguir.

Tabela 4- Resultados do efluente da mistura escala piloto.

\begin{tabular}{ccc}
\hline PARÂMETRO & MISTURA & UNIDADE \\
\hline S. Totais & 2817 & $\mathrm{mg} / \mathrm{L}$ \\
S.V. Totais & 1740 & $\mathrm{mg} / \mathrm{L}$ \\
S.F. Totais & 1077 & $\mathrm{mg} / \mathrm{L}$ \\
S.S. Totais & 95,7 & $\mathrm{mg} / \mathrm{L}$ \\
S.S. Voláteis & 72,5 & $\mathrm{mg} / \mathrm{L}$ \\
S.S. Fixos & 23,2 & $\mathrm{mg} / \mathrm{L}$ \\
S.D. Totais & 2721,3 & $\mathrm{mg} / \mathrm{L}$ \\
S.D. Voláteis & 1667,5 & $\mathrm{mg} / \mathrm{L}$ \\
S.D. Fixos & 1053,8 & $\mathrm{mg} / \mathrm{L}$ \\
Na & 20,6 & $\mathrm{mg} \mathrm{de} \mathrm{Na} / \mathrm{L}$ \\
K & 786,21 & $\mathrm{mg} \mathrm{de} \mathrm{K} / \mathrm{L}$ \\
\hline
\end{tabular}

O efluente tem característica orgânica, em virtude das concentrações dos sólidos voláteis se encontrarem mais elevados em comparação com as concentrações dos sólidos fixos, como foi verificado para o efluente de primeira lavagem. Diferenciando-se as concentrações, que são menores, pois deve ter havido um efeito de diluição.

No quesito tamanho das partículas, os sólidos presentes na primeira lavagem, se encontram em suas formas de menor diâmetro, visto que as concentrações dos sólidos dissolvidos encontram-se mais elevadas que as concentrações dos sólidos suspensos. Tal característica é evidenciada pela elevada quantidade de sais dissolvidos, tanto de sódio quanto de potássio, com o segundo em maior quantidade, como foi verificado para o efluente de primeira lavagem. Diferenciando-se as concentrações, que são menores, pois deve ter havido um efeito de diluição.

Em relação às concentrações de $\mathrm{Na} e \mathrm{~K}$, verifica-se uma pequena concentração de $\mathrm{Na}$ no efluente. Tal fato deve-se ao uso de maior quantidade de $\mathrm{NaOH}$ utilizada na etapa de neutralização do óleo. Referente a concentração de K, observa-se uma alta quantidade do mesmo, devido a sua utilização como parte do catalisador (Metóxido de Potássio) da reação. Apesar de haver uma quantidade retida na glicerina, é através da etapa de lavagem que é garantida a remoção do excesso de $\mathrm{K}$, como foi verificado para o efluente de primeira lavagem. Diferenciando-se a concentração de K, que é menor, pois deve ter havido um efeito de diluição.

Comparando com o efluente da primeira lavagem, com os parâmetros da Tabela 4 (efluente de mistura), verifica-se uma diminuição nas concentrações, excetuando-se S.S. Totais, onde ocorreu um aumento de cerca de 3 vezes. 


\section{CONCLUSÃO}

Após as análises realizadas, constatou-se que o efluente final obtido na produção de biodiesel por transesterificação com catálise homogênea em meio básico na planta piloto da Usina Experimental de Caetés, tem característica orgânica.

Dentre os parâmetros analisados, observa-se que o não enquadramento da maioria nos padrões de emissão e classificação dos corpos hídricos, de acordo com as RESOLUÇÕES CONAMA 430 e CONAMA 357, respectivamente. Dentre o exposto, os únicos parâmetros que se enquadraram nos padrões de emissão de efluentes, foram temperatura e sólidos sedimentáveis.

Os parâmetros analisados ao longo deste trabalho encontram-se extremamente elevados quando comparados aos valores permitidos na legislação. Desta forma, constatou-se que esse efluente possui uma elevada carga tóxica. Assim, avaliou-se que o efluente é um perigo para os corpos hídricos receptores, sendo necessário o tratamento do efluente em estudo, para que o mesmo possa ser disposto, tanto para reuso, quanto para emissão.

\section{AGRADECIMENTOS}

UFPE; ANP-PRH28; LCI; LEAQ; CETENE; Usina Piloto de Caetés.

\section{REFERÊNCIAS}

BOCCARDO, R.C.; PANORAMA ATUAL DO BIODIESEL. Curitiba, PUC-PR, CEFETPR, UFPR, UFSC, 2004. 82p. Monografia (Especialização em Motores e Combustíveis). Programa Brasileiro de Formação em Motores e Combustíveis, Centro Federal de Educação Tecnológica do Paraná, Curitiba, 2004.

BONOMI, A.; POÇO J.G.R.; TRIELLI M.A. Biocombustíveis: a solução brasileira para uma matriz energética sustentável. Rev. Bras. de Eng. Quím: São Paulo. Out. 2006. IPT/SP. p.16-21.

BRASIL, Conselho Nacional do Meio Ambiente - CONAMA. Resolução nº 357, v;lde 17 de março de 2005. Dispõe sobre a classificação dos corpos de água e diretrizes ambientais para o seu enquadramento, bem como estabelece as condições e padrões de lançamento de efluentes, e dá outras providências. Diário Oficial da república federativa do Brasil, Brasília, DF, 17 de março de 2005.

FERRARI, A. R.; OLIVEIRA, V. S.; SEABIO, A. Biodiesel de Soja - Taxa de Conversão em Ésteres Etílicos, Caracterização Físico-química e Consumo em Gerador de Energia. Quím. Nova. vol. 28, n 1, p. 19 - 23, 2005.

HOLANDA, A. Biodiesel e Inclusão Social. Brasília, DF: Câmara dos Deputados Coordenação de Publicações, 2004, p.200. (Caderno Altos Estudos).

JARUWAT, P.; SANGKORN, K.; HUNSOM, M.; Management of biodiesel wastewater by the combined processes of chemical recovery and electrochemical treatment. Energy Conv. Management. 2010, Vol. 51, p. 531-537.

LIMA, P.C.R., 2005. Biodiesel: Um novo combustível para o Brasil, Consultoria Legislativa. Área XII, Recursos Minerais, Hídricos e Energéticos. Fev. 2005. Brasília DF.HARTMAN, L., LAGO, R.C. A . Rapid preparation of fatty acid methyl ester from lipids. Londres : Lab. Pract., v. 22, p. 475-476, 1973. 